\title{
Health And Social Care Partnerships in SCOTLAND
}

\author{
Tom Forbes and Debbie Evans
}

\section{INTRODUCTION}

Since 1997 the development of partnership working across the public sector has been one of the key themes of UK government policy (Balloch and Taylor 2001). One area where partnership working has had a major influence has been in the field of health and social care. Whilst a diverse range of partnership mechanisms have developed between health and social care (Dowling et al 2004), equally diverse is the policy approach taken by each of the devolved areas that constitute the UK (Exworthy 2001). Varying modes of decentralisation have allowed Scotland, Wales and Northern Ireland to promote the modernisation of health and social care to meet the needs of their respective populations (Greer 2004). In Scotland, this resulted from devolution and the setting up of a Scottish Parliament in 1999. Health and social care became devolved matters for the newly formed Scottish Executive.

This article tracks recent changes introduced by the Scottish Executive ${ }^{1}$ between April 2005 and April 2007 to bring health and social care together in a more cohesive package within the context of a political environment that has sought to promote the virtues of partnership working. It focuses specifically upon the implementation of Executive policy which established new Community Health Partnerships (CHPs) as local structures designed to tackle health improvement. Partnership working is unique to Scotland as a key policy driver to deliver public services compared to the rest of the UK (Greer and Rowland 2007). In England and Wales, for example, the market is still the predominant method of service delivery in health and social care (Glasby 2007). As such this merits a closer examination of the implementation of health and social care policy in Scotland and the implications for the use of partnership working to deliver these important public services. The article is structured as follows. Section two provides an outline of the context of health and social policy in Scotland since 1997. Section three details the methods used in the collection and analysis of the data discussed in the article. Section four provides the article's analysis and finally section five provides its discussion and conclusions.

\section{The Context of Health and Social Care Policy in Scotland}

To examine recent developments in Scottish health and social care we need first to return to the aftermath of the 1997 UK General Election. The first White Paper following the election from the then Scottish Office, Designed to Care (Scottish Office 1997), extolled the virtues of 'integrated clinical services which deliver seamless care' (Scottish Office 1997, p.2). Designed to Care was a good old fashioned re-organisation with its main goal the promotion of horizontal and vertical integration in health care delivery (Woods 2001). These changes were designed to reduce the fragmentation that had developed in the competitive market era because of the implementation of UK-wide health policy, and in its place promoted co-operation and partnership working across the Scottish NHS.

Whilst retaining the 15 Scottish Health Boards which assumed responsibility for service planning and health improvement, existing NHS Trusts were reduced in number from 47 to 28 and a new form of

Tom Forbes is a Senior Lecturer in Business and Management at the University of Stirling who has research interests in health policy and management and more recently has been working in the field of health and social care. Debbie Evans is a former MBA student at the University of Stirling.E-mail-t.m.forbes@stir.ac.uk

${ }^{1}$ The Scottish Executive is referred to throughout this article as 'the Executive'. 
Trust, the Primary Care Trust, was created which was responsible for delivering GP-based services alongside care in the community (Scottish Office 1997). At an operational level, GPs were invited to form Local Health Care Co-operatives to deliver primary and community care services across a defined area. The Co-operatives were separate management entities but were intended to be an integral part of the Primary Care Trust (Bruce and Forbes 2001). Co-operatives were vehicles for the implementation of local planning and health improvement and steps were taken to increase the effectiveness of their role with agreed national and local standards (Hudson and Hardy 2001). In particular, Co-operatives were given a degree of discretion to adopt governance arrangements to suit local health circumstances indicating an increased emphasis on a decentralisation of responsibilities by the then Scottish Office.

Subsequent post-devolution policy in Scotland built on this framework, and Our National Health: A Plan for Action, A Plan for Change (Scottish Executive 2000a) undertook to legislate to remove existing barriers to joint working that might hinder joint planning between health and social care. Further, it announced the intention to abolish NHS Trusts and establish new 'unified' NHS Boards across Scotland so bringing local primary and secondary health care provision into a single system of governance. Local Authority involvement in health and social care planning was strengthend by the requirement that these new unified NHS Boards had Local Authority membership and that 'Local Authorities would [now] have a strong voice on the new [unified] Health Boards' (Scottish Executive 2000a, p.29). The 2002 Community Care and Health (Scotland) Act (HMSO 2002) provided the basis for closer joint working between NHS Boards and Local Authorities by introducing a series of 'flexibilities' designed to break down some of the perceived barriers to collaboration between health and social care. NHS Boards and Local Authorities could now pool budgets and enter into arrangements for the joint management of services.

The Joint Future Group was set up by the Executive in 2000 to find ways of improving joint working between the Scottish NHS and Local Authorities in an attempt to deliver modern and effective integrated services to the elderly. The Joint Future Group reported in 2002 and suggested that there was a long way to go in terms of consistently delivering quality services to people across Scotland (Joint Future Group 2002, p.8). The essence of Joint Future sought to establish formal partnerships between NHS Boards and Local Authorities. The Executive accepted the findings of the Joint Future Group and subsequently health and social care partnerships were established with all NHS Boards and the 32 Local Authorities in Scotland (Scottish Executive 2000b). This also allowed for coterminosity between NHS Boards and Local Authorities boundaries which was thought would lead to better joint planning and delivery of services. At this time a national partnership was formed between the Executive, NHS Scotland and the Convention of Scottish Local Authorities which underlined the emphasis on partnership working from the key players in the delivery of health and social care policy in Scotland.

To improve the operational aspects of these partnerships, the Executive issued guidance with respect to joint working and finance (Scottish Executive 2001). New financial mechanisms were introduced based upon a system of aligned budgets but with an aspiration to move to a more integrated system of pooled budgets. This would be underpinned by a stronger lead from the Centre through national financial, planning, and management frameworks designed to forge relationships between agencies, set objectives and monitor performance (Scottish Executive 2001). To ensure the implementation of its policy, the Executive developed a means of monitoring the performance of the health and social care partnerships. Comprehensive joint planning initiatives were enabled with the setting up of the Joint Performance Information and Assessment Framework (Scottish Executive 2003a). The Framework provided a national assessment of how effectively health and social care partnerships were working together to deliver improved benefits to individuals and their carers. From 2004 the partnerships were to include all community care groups (Scottish Executive 2004a).

\section{Community Health Partnerships}

In 2003 Partnership for Care (Scottish Executive 2003b) was published which set out the Executive's vision for the NHS in Scotland. At the heart of this vision was health improvement. Health improvement is a complex area but is affected by life circumstances and lifestyles choices. Partnership for Care proposed that Health Boards should build on the successes of their existing Local Health Care Co-operatives and recognise areas for improvement as the first step towards creating a new type of partnership model, the Community Health Partnership. These were to be the key drivers in health improvement by providing a focus for service integration between health and social services through developing closer working relationships with primary and secondary care, Local Authorities, the 
Voluntary Sector and local communities. All agencies were to be viewed as 'equal' partners and Community Health Partnerships would have 'a new and enhanced role in service planning and delivery, working as part of decentralised but integrated health and social care systems' (Scottish Executive 2002, p.4) and were eventually to 'establish substantive partnerships with local authority services, act as a focus for integrating primary and specialist health services at a local level, and play a pivotal role in delivering health improvement for their local communities' (Scottish Executive 2003b, p.35). Each NHS Board would be required to submit a 'Scheme of Establishment' to the Executive for approval (Scottish Executive 2004b). The Schemes set out the number of Partnerships that would be created in each of the Health Boards including services covered, organizational arrangements and accountability and governance arrangements. To date 40 Community Health Partnerships have been established with the majority co-terminous with Local Authorities. Unlike Local Health Care Cooperatives before them which were voluntary groupings of GPs, Community Health Partnerships are statutory organizations serving populations in urban, rural and Island communities and have absorbed much of the earlier joint future arrangements in health and social care.

During the Spring of 2004 the Executive issued draft guidance on the possible roles and future of Community Health Partnerships and entered into a consultation period with a range of stakeholders including Health Boards, Local Authorities, health professions, the voluntary sector and other interested groups. The majority of respondents were from NHS Boards. Included in the guidance was the requirement that each Partnership should have a Committee to drive service improvements locally and a smaller management committee charged with the operational management of the organisation. Membership of these Committees had an emphasis on NHS professionals and managers. New mechanisms to include the public and carers were established through the development of a Public Partnership Forum in each Community Health Partnership. This consultation period ended in the Autumn of 2004 with the publication of formal Community Health Partnership Guidance (Scottish Executive 2004b).

The guidance tended to be largely prescriptive and had changed little from the earlier version, describing an essentially 'health' based Partnership model that focused on primary health services with some linkage to Local Authority social services. The guidance set out Partnerships as sub-committees of Health Boards with delegated responsibility for service delivery. Their accountability, governance arrangements and membership all reflected this structure. This resulted in criticism and disappointment from NHS Boards and Local Authorities who were seeking the opportunity to be more innovative with their Partnership designs. A number of NHS Boards and Local Authorities began to examine the potential for the development of alternatives to the 'health' only Partnership resulting in the emergence of a number of Partnership models with service designs that differed in the degree of integration chosen by NHS and Local Authority partners. These Partnership models are, briefly:

Health only Community Health Partnership: has single accountability and governance arrangements with delegated responsibility for services from NHS Boards which links community planning with health input to Joint Future. Its main focus is on providing primary health services.

Partially Integrated Community Health Partnership: there is agreement between an NHS Board and Local Authority to work towards integration with several services already integrated at a local level with, for example, either a single management structure for mental health and learning disability or integrated team leaders for similar services. Accountability for the delivery of services is still to the NHS Board

Integrated Community Health Partnership: an NHS Board and Local Authority develops joint management arrangements with a single manager from the outset and primary health services and social services are merged in one organization with their parent bodies retaining statutory responsibilities. The NHS Board and Local Authority delegates operational management and service delivery powers to the Partnership which has dual accountability and governance structures to reflect this arrangement. There is no change of employer for staff and each Partnership operates within its parent bodies' strategic framework. These Partnerships are typically re-cast as Community Health and Care Partnerships or Community Health and Social Care Partnerships. 


\section{METHOD}

The data presented in this article has been developed from an on-going longitudinal study that began in 2004 and is examining the emergence of the Partnership model in Scotland. The main method of data collection was based on semi-structured interviews (Mays and Pope 1997). Interviews were carried out with three Community Health Partnership Directors, three Local Authority senior managers and three NHS Board senior managers. Each interview focused on the first 18 months of Partnership operation and lasted approximately one to one and a half hours. The selection of Partnerships, Local Authorities and NHS Boards was intended to offer a broad view of the key issues being experienced in implementing the partnership agenda in Scotland and to illustrate similarities and differences. All the Partnerships were recently established and the areas discussed during interview focused on partnership development and partnership working. The data is presented as a connected narrative account with content analysis used to aid combination of data for analysis (Easterby-Smith et al 1993). As the information given during the interviews was confidential and to preserve the anonymity of participants, pseudonyms have been used. This extended to organisational documentation which provided background information and as such has not been referenced. The Partnerships reported are as follows:

\section{Alpha: a non-integrated Community Health Partnership}

Alpha became operational in December 2005 as a 'health-only' Partnership, allowing the opportunity to plan and manage the provision of health services in the Alpha area within a single health organisation. The proposal to establish the Partnership was built on existing and well-established joint arrangements with Alpha Council. With high levels of smoking, obesity and alcoholism, it had an overall health profile that was the third worst in Scotland. Realising that solving these issues necessitated common planning structures, local health services and social services had already built strong links and joint working arrangements were in place for the planning of children's services, across older people's teams and in addictions. The establishment of a joint manager post for the community addiction team with responsibility for all health and social work in this field for the whole of the Alpha Council area set the tone for creation of the future Partnership.

Both the NHS Board and Local Authority were keen to develop an integrated Partnership model. However, at the time there were two health boards coterminous with Alpha Council, Gamma NHS Board and River NHS Board. Although both met regularly to develop policy that affected their populations, it was not clear to Alpha Council that the two Health Boards could form a cohesive partnership and there was a perceived risk in service provision for the Local Authority if things went wrong. Thus an integrated model was not pursued and the 'health' only Partnership model was taken forward with accountability to the Health Board for delivering health services. Nonetheless, strong partnership working with Alpha Council has been maintained and opportunities for service-specific integration have contined to be explored, for example in Learning Disabilities and in Mental Health. Local health service providers also continue to support the view that an integrated structure could offer significant service and resource benefits.

\section{Beta: a partially integrated Community Health Partnership}

Beta was established in April 2005 and is one of three Partnerships operating within Castle NHS Board. Again, there was a strong history of partnership working to support formation of the Partnership. Integrated teams with pooled budget arrangements already existed for learning disabilities and adult mental health. Indeed, for Beta joint working in mental health was an example of best practice upon which subsequent formation of the Partnership was based. Castle's approach to Partnership development was described as 'inclusive'. A Partnership steering group had been set up to oversee Partnership development in the Castle Board area and had strong Local Authority representation with council members involved with Partnership development groups. Local Authority management also participated heavily in smaller Partnership development programmes run by Castle NHS Board. During the Partnership development period the potential formation of an integrated Partnership model was explored and possible governance structures examined. The Local Authority, whilst not prepared to devolve its services to the existing health service providers, was prepared to consider the creation of a new partnership structure. Legal advice was sought to examine the potential for an integrated Partnership structure. However, at the time it was not conclusive that the arrangements that the NHS Board and Local Authority wanted to pursue would be possible. A pragmatic approach was subsequently taken to first submit its Scheme of Establishment as a nonintegrated Partnership and to consider the potential for moving to an integrated Partnership in the future. 


\section{Gamma: an integrated Community Health and Social Care Partnership}

Gamma Community Health and Social Care Partnership became operational in April 2006. There had been a ten year history of progressive partnership working between Gamma NHS Board and Gamma Council and since the mid 1990s the NHS and Local Authority had developed integrated strategic planning, joint community care plans and financial frameworks. Indeed there was a form of joint governance already in place for health and social work services with a forum made up of NHS senior managers and elected members which allowed high level planning of local service integration. From a service perspective there was integrated provision in learning disabilities, in addictions, in some areas of older people's services and in mental health. The introduction of Partnership guidance by the Executive offered the potential for a step change in the level of health and social service integration that had already been achieved and which could then be applied to an entire organisation rather than to specific service areas. However, given their vision for integrated service provision, Gamma NHS Board and Gamma Council found the Guidance to be too limiting based on a 'health'-only Partnership design. There was local agreement that NHS and Local Authority responsibilities could be brought together into an 'integrated' Community Health and Social Care Partnership which was subsequently formed building on each partner's experiences of joint working, while maintaining the integrity of two separate organisations. Individual agency accountability was retained for statutory functions, resources and employment issues. However, dual accountability and governance structures were established for the provision of joint health and social services. The resultant organisation offered considerable scope to shift the institutional-based paradigm of service delivery to services organised around the needs of service users. With high levels of inner city deprivation, it was argued that Gamma Community Health Partnership had a needs profile that differed from much of the rest of the country and an innovative solution was developed to respond to the specific challenges faced in the area.

\section{ANALYSIS}

As indicated earlier, the interviews focused on partnership development and partnership working. Using these two broad areas, a number of common issues emerged which we have developed into themes. This has allowed us to offer some novel insights into the implementation of Executive policy and how this change was being operationalised on the ground.

\section{Clarity of Community Health Partnership guidance}

All three Community Health Partnerships were critical of Partnership guidance issued by the Executive. Alpha Community Health Partnership described it as 'prescriptive in some areas and inadequate in others'. Beta NHS Board suggested that a key area of weakness was the clarity of the Partnership agenda, in particular relating to the level of power and responsibility that Health Boards should devolve to the Partnerships. Beta Community Health Partnership was even more forceful by stating that the guidance was "not delivering on the vision of Community Health Partnerships. It portrayed them as nothing more than big Local Health Care Co-operatives and containing nothing supportive to the potential impact of the new partnerships'. Gamma Community Health and Social Care Partnership, given its early move to an integrated model, found the guidance to be 'particularly poor with respect to supporting the integrated Partnership model'. Gamma Partnership claimed that since submitting its Scheme of Establishment there had been very little contact with or follow up by the Executive and, as such, they had proceeded largely independently. This is an interesting point. The Executive did have a consultation period but appears not to have included in the final guidance any mechanism which would allow NHS Boards and Local Authorities scope to develop anything other that a 'health'-based Partnership model. This was arguably a missed opportunity by the Executive and gives the impression that the 'health'-only Partnership model was already favoured.

However, despite criticisms of the Partnership guidance, the 'hands-off' approach to policy implementation taken by the Executive was broadly welcomed. All Partnerships and NHS Boards were positive towards the Executive's overall approach in supporting the partnership agenda. Alpha Partnership was strongly supportive of the Executive's aims around Partnership creation and, while initially critical of the Partnership guidance, Beta Partnership praised the 'obvious, logical development path' that the Executive was following and appreciated the consistent direction of travel. Beta Partnership believed that in its case, the Executive had been somewhat 'more controlling' possibly because the Beta Partnership was initiated much earlier and was also more in line with Executive guidance. Gamma Partnership stated that the Executive had developed 'a coherent, collaborative policy structure that was well understood'. An important factor was that the partnership agenda was clearly 
the central theme of Executive health and social care policy. Both Beta and Gamma Partnerships suggested that they had felt empowered to develop their own model, although Gamma Partnership indicated that there had been some recalcitrance from some quarters of the Executive towards its integration proposals as they were significantly different to that advocated by the Guidance. Some elements within the Executive were described as 'lukewarm' regarding the development of the integrated model and as, at one point, attempting to de-rail its implementation. However, Gamma NHS Board had successfully courted Scottish Ministers and senior civil servants keeping them fully briefed them of the rationale behind their integrated Partnership. As a result, Scottish Ministers were largely satisfied with the approach taken by Gamma NHS Board and the subsequent development of the integrated model was allowed to progress unchallenged. This recalcitrance raises questions over the political ramifications of this apparent divergence from policy, but also why the opportunity was not taken to examine the Gamma Partnership approach in more detail given the potential for knowledge transfer and the rolling out of the integrated model to NHS Boards and Local Authorities who were keen to explore this path.

\section{Local Authority Engagement}

Although the basis for joint working was strong for Alpha and Beta Partnerships, both had experienced some resistance from their Local Authority partners to devolving social services to their Partnerships. The root cause was a lack of Local Authority trust in the ability of the existing health service to manage devolved services effectively. Furthermore, unlike Joint Future, there was no legal requirement for Local Authorities to engage with the Partnership agenda, a major hurdle to the continued development of health and social care partnerships in Scotland. Joint Future had the agreement of the national partners in terms of implementation, but no similar agreement had been reached on the development of Partnerships as key vehicles in delivering health improvement. Clearly a paradox emerged here with the Executive having already integrated the NHS to allow for the improved service delivery, and although keen in its desire to improve joint working between the two main partners in health and social care, not recognizing the need to provide some mechanism to bring them together. As one Local Authority commented, Partnerships were 'perceived as a creation of NHS Scotland and thus primarily designed for meeting health service need'. However, in neither case did Local Authority reticence preclude service-specific joint working but it did prevent early implementation of an integrated Partnership model in Alpha and Beta Partnerships mainly because local councillors were not keen to delegate or 'give' any decision making over social services to the NHS. Related to this was the fact that the pace of change with respect to Partnership formation had generated a degree of tension amongst Local Authority partners at all locations. The NHS had already gone through repeated organisational change since 1997 and arguably was more used to the pace of change compared to the Local Authorities who had become more settled since the last major re-organisation in Local Government in Scotland in 1996. There was also some mention of issues arising from 'cultural and political differences', although it was felt that the potential of these as partnership stumbling blocks was generally over-emphasised. Practitioners driven by the benefits of the Community Health Partnerships had usually been able to overcome any cultural differences that might have existed and any that remained tended to be at 'macro' level, for example at the officer-councillor interface.

\section{Financial Matters}

Two of the three Partnerships drew attention to their budget setting processes. For Beta Partnership the problem had centred on the fact that Local Authority budgets tended to be pre-allocated for specific areas of service provision whereas NHS funding could be more freely applied. The fact that the NHS and Local Authorities had different financial systems and planning cycles did not help matters as funding could be released at different times and if partners were under financial pressure the Partnerships might not have been able to deliver service improvements. Earlier in the article we alluded to the availability of 'flexibilities' to remove some of the perceived barriers to joint working in health and social care. Surprisingly there was no mention in the interviews either of what the flexibilities had to offer, nor of any intent to use them. Although designed to be used with Joint Future this could have been one way of resolving the problems of different financial cycles and reporting mechanisms, through for example the pooling of budgets for specific services. It is a major weakness of Partnership for Care and the Community Health Partnership guidance that no provision was made to overcome this hurdle with a commitment for the joint budgeting of services. Even with Gamma as an integrated Partnership, both the NHS Board and Local Authority had similar financial issues to the non-integrated Partnerships. This may suggest that until common funding arrangements are in place, this problem will remain and could jeopardise the health improvement agenda of the Partnerships. 
In addition, Beta Partnership claimed that where discretionary Local Authority funding had existed, it was not necessarily being diverted to support health priorities. However, again, despite these tensions and a lack of funding from the Executive to 'pump prime' Partnership formation, this was not seen as a major hurdle and it was hoped that once the Local Authorities saw the Partnerships up and running they would relax their attitudes to releasing funding for Partnership services.

\section{Organisational issues}

Whilst the Partnerships raised organisational issues in relation to partnership development, they were, not surprisingly, specific to partnership working in general. For Beta Partnership, the smallest Partnership in this study, difficulties centred on finding adequate capacity to cope with the additional workload brought about by the new partnership agenda. The need was expressed for increased managerial and clinical capacity as well as strong local leadership to facilitate the required changes. For Gamma Partnership, organisational issues mainly related to managing the changing function of Gamma Health Board. The emerging Partnership was evoking considerable tension, particularly with Gamma Health Board's need to devolve responsibilities to the new organisation while at the same time undergoing a major re-organisation. It was challenging for staff at NHS Board level to still feel in control of overall health service provision as it became devolved across the Gamma Partnership. For ease of comparison, Table 1 summarises the partnership and policy issues raised by the three Partnership during the interviews.

Table 1

Partnership and policy issues raised by the Community Health Partnerships

Partnership Issue

Engagement of local authority partner

Imbalance of partner input

Conflicting partner priorities

Cultural issues

Structural issues

Financial Issues

Performance measurement
Raised by Community Health Partnerships

Some resistance by local authorities to devolve social service responsibilities to Partnerships

Perceived NHS dominance of Partnerships model Partnerships primarily designed to meet health service needs

Some evidence of differing local authority priorities and budget allocations

Some lack of trust in the ability of local health services to perform social service functions

Sourcing adequate staffing to plan, manage and operate Partnerships priorities; managing internal staff reorganisation and shifting responsibilities

Budget setting process: preallocated/ring-fenced funding issues

Difficulty in combining local and national targets; difficulty in finding measures to demonstrate Partnership effectiveness 
[Table 1 continued]

Policy issue

Insufficient depth of policy/guidance

Inadequate performance framework
Insufficient clarity of

Partnership guidance (however,

'hands-off' approach

considered largely acceptable);

need for a requirement to

ensure compulsory

involvement of local authorities

Requirement to support

development of solid

performance management

framework

\section{Partnership Working}

The day to day working of these new partnerships also provided interesting insights into how the new Partnership were bedding in. Unsurprisingly, given the early stages of their development, priorities were centred on establishing new working arrangements. In the case of Alpha Partnership these included establishing clear structures and processes for the Partnership Committee and a number of fora for staff and public involvement in decision making. Gamma Partnership retained a similar focus on developing an appropriate organisational form and had become embedded in local community planning structures which had engendered greater local discussion around health improvement priorities. Beta Partnership, now 18 months after establishment, was further advanced. It was described as 'already playing a significant role in widening the debate beyond basic provision of primary care across [Castle Health Board]'. Public and patient forums were also well developed with active local participation in local decision making. In all cases staff were described as 'enthusiastic' towards the opportunities presented by the new partnership structures with the partner organisations actively engaged in developing joint planning strategies and performance frameworks. However, Gamma Partnership indicated that in some services that were now jointly managed, staff had 'felt threatened in relation to the new working arrangements, particularly when not directly managed by someone from their own profession or service background'. In such instances the Partnership was having to establish significant organisational development interventions to work with the various professional groups involved.

All Partnerships indicated a strong sense of local empowerment. This was described as present across their Partnership management teams and critical to the drive to develop and deliver improved local services. Certainly in the case of Gamma Partnership, both partners were 'confident that the right model was being developed to make a difference to health and social work service delivery'. Although both Alpha and Beta Partnerships indicated their intention to explore adaptations to their Partnership models, the overall enthusiasm towards partnership working was still strong within the constraints of each Partnership.

\section{Developing a Performance Management Framework}

Although it is still early days, all three Partnerships were struggling to develop and implement an effective performance management framework to monitor the progress of their partnerships. The key issue appeared to be how to match national targets with local priorities. This was also down to the seemingly relaxed Partnership implementation style of the Executive. All the Partnerships had absorbed the Joint Future partnerships and with this the existing Joint Performance Information and Assessment Framework. The Framework was deemed inappropriate given the wider remit of Partnerships. No performance management system had been suggested by the Partnerships guidance. This problem could have perhaps been foreseen and suggests a lack of joined-up thinking by the Executive trying to impose a new system on top of an existing system which itself had only recently been established. While Gamma as an integrated Partnerships had attempted to put together a joint performance management framework, it had not yet been able to localise the high level Health Board performance targets needed to create adequate local responsiveness. 
All interviewees therefore realised the difficulties associated with outcome measurement and that this was likely to be a challenging task for the new partnerships to demonstrate their effectiveness. Within Beta Partnerships it was felt that national target achievement was 'demanding high energy and much effort'. Collectively, all three Partnerships expressed the need for the Executive to focus on encouraging development of a solid performance management framework. Although recent developments in policy had maintained the profile of Partnerships to deliver health improvement (Scottish Executive 2005a), all three Partnerships suggested that help was needed to interpret the action points contained within Delivering for Health (Scottish Executive 2005b). The introduction of improved public accountability measures, in response to criticism that performance management needed to be more robust, 'did not go far enough'. More stringent measures would be needed to 'tighten a loose system' if (as claimed by the then Health Minister Andy Kerr) the effectiveness of the Partnership model needed to be demonstrated in the next two to three years (Kerr 2005). Alpha Partnership in particular expressed concern that the 'patchwork' quilt of Partnership models evolving to meet local need because of the Executive's 'hands off' approach would need to be strongly managed and it was questioned whether the Executive 'had the capability and capacity to deliver in this area'. Otherwise future tensions were foreseen within the Executive which could result in a swing towards more central control of the partnership agenda.

\section{DiscuSSION AND CONCLUSION}

This article has examined recent developments in health and social care partnerships in Scotland focusing on the new Community Health Partnerships. Beginning with the Scottish Office and continuing with the Executive, health and social care policy has been successfully built over a number of stages. This has led to a consistent approach to improve joint working arrangements between the NHS and Local Authorities. Many of these systems are now coterminous with Local Authorities which has also facilitated an improved and more focused approach to local planning and delivery of services. Although the implementation of health and social care policy has largely been top down since 1997 there does appear to have been a change in emphasis by the Executive towards a more relaxed implementation 'style' with regard to Community Health Partnerships. The Executive has allowed a degree of flexibility to suit local contexts rather than the 'one-size-fits all' approach of previous years and we have seen a number of Partnership designs emerging. Where there was a good history of working relationships between NHS and Local Authorities there has been a willingness to explore different levels of integration and there is now the acknowledgement that integration is an aspiration for many health based and partially integrated Partnerships. Although their structures are different, all the Partnerships in this study faced similar issues. These included Local Authority suspicion in the early days of the Partnership, problems of resourcing services within the Partnership and a recognition that some form of performance measurement is now needed to determine how successful Partnerships are in improving health. These issues are also not that uncommon and are inherent in health and social care joint working arrangements (Glendinning et al 2005). There were also several paradoxes present which led to many Partnerships finding it difficult to fully embrace the partnership agenda set out by the Executive. The Partnership Committees, for example were populated by NHS professionals at the expense of Local Authorities, the voluntary sector and patient groups. This almost certainly sent the wrong message about partnership working to other partners and gave a clear signal that Partnerships were a health rather than a health and social care partnership. Most fundamentally the Executive did not recognised the need to involve the Local Authorities in the Partnership development process, as they had done with Joint Future through the national partners. This resulted in many Local Authorities viewing the advent of Partnerships as simply yet another NHS change rather than as a means to jointly tackle health improvement. If the Executive was serious about joint working some form of mandate or other means to involve Local Authorities was required at an early stage. With a 'looser' policyimplementation process and the emphasis on a health-based Partnership model, the Executive also unwittingly demonstrated a lack of vision of possible Partnership arrangements. This was a missed opportunity to build on previous health and social care partnership working by NHS Boards and Local Authorities and the Executive may well having been caught on the back foot with the level of innovation willing to be attempted by some NHS Boards and Local Authorities. With a clear bias towards health-only Partnerships there will never be true health and social care partnerships, which raises serious questions about the level of joined-up thinking within the Executive, giving, as it does, scant regard to how the Local Authorities in particular can be engaged in the health improvement agenda that Community Health Partnerships are supposed to be tackling. Both the NHS and Local Authorities have a key role to play here and do so via common platforms such as community planning. 
Short of combining health and social care services into one organisation there will always be challenges for Local Authorities to engage in the partnership agenda under the current arrangements. New guidance from the Scottish Government is long overdue particularly in relation to potential Partnership designs and suitable governance and accountability arrangements which could be fruitful in bringing Local Authorities closer to being comfortable with developing integrated Partnership models.

What is certain is that the Scottish Executive was firmly committed to the Community Health Partnership as the mechanism for providing service integration between health and social care. Publication of The National Framework for Service Change in the NHS in Scotland (Scottish Executive 2005a) and Better Health, Better Care: an Action Plan (Scottish Government 2007) has set Community Health Partnerships firmly at the centre of current Scottish health reform. Partnerships are now viewed as key drivers for the modernisation of Scotland's future health and social care services. Of course Partnerships as models of partnership working are as yet untested in terms of their efficacy in delivering health and social care services and we have seen a number of conundrums that will need to be addressed. As with Joint Future the Scottish Government is relying on untested mechanisms to adequately demonstrate the efficacy of partnership working to deliver public services. There are few reports available that demonstrate the effectiveness of partnership working in delivering public services. Moreover where evaluations have been attempted the results are generally inconclusive (Glendinning et al 2002, ODPM 2006). The potential result is political commitment to untried models and care will be needed to ensure that the benefits are tangible and long term.

This article has indicated several interesting developments in relation to Scottish health and social care. However, it has its limitations. Although part of a wider study, constraints on space, choice of data presented and small sample size may not provide a full analysis of all current Partnership developments. There are several groups and organisations that have not been discussed but nonetheless have an impact on the operation of Partnerships. We have not for example examined the role of the voluntary sector, a key player in the deliver of social services, nor the development of the Public Partnership Forums as vehicles for public engagement with the Partnerships. However, what we have provided here is a snap-shot of some of the key issues affecting the new Partnerships. More studies will be required to examine the efficacy of these partnership models in bringing about changes in health improvement.

\section{REFERENCES}

Balloch, S. and Taylor, M. (2001). Partnership Working: Policy and Practice. The Policy Press, Bristol.

Bruce, A and Forbes, T. (2001). From Competition to Collaboration: in the Delivery of Health Care: Implementing Change in Scotland, Scottish Affairs, Issue No 34, 103-120.

Dowling, B, Powell, M. and Glendinning, C. (2004). Conceptualising successful partnerships. Health and Social Care in the Community, Vol 12 No 4, 309-317.

Easterby-Smith, M. Thorpe, R. and Lowe, A. (2003). Management Research: An Introduction. London, SAGE.

Exworthy, M. (2001). Primary Care in the UK: understanding the dynamics of devolution. Health and Social Care in the Community, Vol 9 No 5, 266-278.

Glasby, J (2007) Commentary: Reply to Editorial Guus Schrijvers, International Journal of Integrated Care, Vol 7 , p 1.

Glendinning C., Hudson B., Hardy B et al (2002) National Evaluation of Notifications for Use of the Section 31 Partnership Flexibilities of the Health Act 1999: final project report. National Primary Care Research and Development Centre/ Nuffield Institute for Health, Manchester/Leeds.

Glendinning C, Hudson, B and Means, R. (2005). Under Strain? Exploring the troubled relationship between health and social care. Public Money and Management, 1, No 4, 245-251.

Greer, S.L. (2004). Four ways to bet: how devolution has led to four different models for the NHS. The Constitution Unit, UCL.

Greer, S., Rowland, D. (2007) Devolving Policy, Diverging Values: The Values of the United Kingdoms National Health Services. The Nuffield Trust, London.

Mays, N, Pope, C (1996). Qualitative Research in Health Care, BMJ Publishing Group, London.

HMSO (2002). Community Care and Health (Scotland) Act 2002. London. The Stationery Office.

Hudson, B. and Hardy, B (2001). Localization and Partnership in the 'New National Health Service: England and Scotland compared. Public Administration, 79 No 2, 315-335.

Kerr, A (2005) Speech to the Association of CHPs Conference. 21 Sept. 2005. 
ODPM (2006) National Evaluation of Local Strategic Partnerships: Formative Evaluation and Action Research Programme 2002-2005. Final Report . Office of the Deputy Prime Minister, Jan 2006. Website: www.opdm.gov.uk

Joint Future Group (2000) Community Care: A Joint Future. available at: www.scotland.gov.uk/library3/social/rjfg-00.asp, accessed, September $21^{\text {st }} 2007$.

Scottish Executive (2000a). Our National Health: a plan for action, a plan for change. Edinburgh. The Stationery Office.

Scottish Executive (2000b). Report of the Joint Future Group. Chair: Ian Gray, Edinburgh: The Stationery Office.

Scottish Executive (2002). Community Health Partnerships. Minister for Health and Community Care, Letter, 18 July.

Scottish Executive (2001). Joint Resourcing and Joint Management of Community Care Services. CCD7/2001, Edinburgh: The Stationery Office.

Scottish Executive (2003a). The Joint Performance Information and Assessment Framework (JPIAF). Circular No. CCD 1/2003 Joint Future Unit, Edinburgh, The Stationery Office.

Scottish Executive (2003b). Partnership for Care. Edinburgh: The Stationery Office.

Scottish Executive Chief Executive Officers NHS Scotland and COSLA, (2004a). Reinvigorating the Joint Future Agenda. Letter, 4 March.

Scottish Executive (2004b). Community Health Partnerships Statutory Guidance. Edinburgh, Scottish Executive.

Scottish Executive (2005a). Building a Health Service Fit for the Future: a National Framework for Service Change in the NHS in Scotland ('The Kerr Report'). Edinburgh: The Stationery Office.

Scottish Executive (2005b). Delivering for Health. October 2005, Edinburgh: The Stationery Office.

Scottish Government (2007). Better Health, Better Care: An Action Plan, Edinburgh: The Stationery Office.

Scottish Office (1997). Designed to Care: Renewing the National Health Service in Scotland. Edinburgh: The Stationery Office.

Woods, K. J. (2001). The development of integrated health care models in Scotland. International Journal of Integrated Care, 1, 1-10.

April 2008 